\title{
Investigating the Prevalence and Risk Factors of Depression Symptoms among NCAA Division I Collegiate Athletes
}

\author{
Charles E. Cox ${ }^{1}$, Lindsay Ross-Stewart ${ }^{2}$ and Brad D. Foltz ${ }^{3}$ \\ 1. Department of Education, Florida State University, Tallahassee, FL 32306, USA \\ 2. Department of Applied Health, Southern Illinois University Edwardsville, Edwardsville, IL 62026, USA \\ 3. Athletic Department, University of Oklahoma, Norman, OK 73019, USA
}

\begin{abstract}
This study aimed to determine an overall prevalence rate for depression symptoms among National Collegiate Athletic Association (NCAA) Division I collegiate athletes while also assessing various risk factors that may increase an athlete's vulnerability to depression. Using a sample of 950 NCAA Division I athletes, it was found that $33.2 \%$ of athletes experienced symptoms of depression, contradicting findings from previous studies that have suggested a prevalence rate lower than the general college population. Female athletes $(P=0.00)$, underclassmen $(P=0.01)$, recently injured athletes $(P=0.05)$, and in-season athletes $(P=0.05)$, were all found to experience higher rates of depression symptoms than other athletes. It was found that $25.7 \%$ of athletes did not know how or where to access mental health treatment at their university, and $44.5 \%$ had received no mental health education from their athletic department. The results from this study suggest that depression is a more significant issue in college athletics than previously thought, and they highlight the need for continued improvements to be made in both the understanding of mental health issues in college athletics and the services that are provided to athletes.
\end{abstract}

Key words: Depression, college athletics, injury.

\section{Introduction}

The mental health of the nation's collegiate athletes is a subject that has garnered significant media attention in recent years [1, 2]. A recent study [3] investigating depression rates in current and former college athletes, found that $16.77 \%$ of current athletes had Wakefield Depression Scale scores consistent with depression, compared to just $8.03 \%$ of former, retired athletes, suggesting that engagement in college athletics may contribute to increased susceptibility to depressive symptoms. This suggestion is further strengthened by the findings of a more recent study, which concluded $23.7 \%$ of current college athletes at a single institution displayed clinically relevant symptoms of depression [4].

Corresponding Author: Lindsay Ross-Stewart, assistant professor, research field: sport psychology.
College is already considered an at-risk period for the development of depression symptoms [5, 6]. In a 2014 nationwide survey of college students, the American College Health Association [7] found that over $30 \%$ of college students reported feeling significantly depressed at some point during the previous 12 months. In addition to the risk factors faced by non-athlete students, the daily demands placed on college athletes-both physical and psychological-may represent additional risk factors that increase vulnerability to depression $[8,9]$. The national governing body for college athletics, the National Collegiate Athletics Association (NCAA), has acknowledged this fact, and in 2013 they inaugurated the Mental Health Task Force, designed to discuss the mental health issues of college athletes and develop strategies for education and research in this area. Furthermore, in 2014 the NCAA's Sport Science 
Institute produced Mind Body and Sport: Understanding and Supporting Student Athlete Mental Wellness, a guide to student-athlete mental health, and distributed this resource to approximately 1,100 athletic directors [10]. All this suggests an apparent move away from the negative stigma that traditionally accompanies mental illness issue in sports [11] and a desire to identify potential depression risk factors in college athletes. However, research directly examining the prevalence and severity of depression symptoms among this population has yielded somewhat contradictory results.

One possible explanation for this variance in reported data is that college athletes still appear to be reluctant to seek out help for mental health concerns and harbor significantly less positive attitudes toward help-seeking behavior and counseling outcomes than non-athletes [12]. It has also been suggested that freshmen are a particularly at-risk population, as they may feel a need to prove they are mentally tough enough for the rigors of college athletics and are therefore reluctant to admit needing help [13]. It is therefore possible that athletes are ignoring or underreporting psychological distress due to a negative stigma attached to admitting needing assistance for such problems.

Certain athlete-specific risk factors have been highlighted in a study exploring the experiences of 10 current and former Division 1 female collegiate athletes who self-identified as suffering from depression [14]. Some of the major issues the athletes described were, feeling overwhelmed by the daily demands and stressors of college athletics, feeling the demands of perfectionism, and feeling increased self-criticism when failing to meet personal goals. The participants also described challenges to their identity either through injury or poor performance. While causation cannot be assumed from the findings in this study, certain common issues experienced by athletes suffering from depression are identified. The results from existing research into the psychological impact of four specific areas-daily stress, injury and athletic identity, and fear of failure, mental health care accessibility and education-demonstrate the significant effect of these unique stressors and highlight the clear need to increase our understanding of depression in college athletics.

\subsection{Daily Stress}

It has been shown that students who perceive themselves as stressed exhibit lower self-esteem and are less likely to practice healthy behaviors than non-stressed students [15]. In college athletics, academic demands (e.g., missing class or making up for missed assignments due to athletic travel commitments) and physical demands (e.g., not having sufficient time to successfully combine athletics and academics) are cited as significant causes of stress [16]. These stressors have been reported to affect the mental and emotional health of college athletes, potentially resulting in outbursts of anger, excessive anxiety, frustration, irritation, fatigue, headaches, and digestive problems [16]. Freshman athletes are also found to experience unique stressors - such as the loss of star status experienced in high school and conflicts with new coaches and teammates - that potentially cause them to engage in poor coping techniques such as skipping class, drinking, or withdrawing from their team or sport altogether [13]. The potential psychological effect of this stress is further highlighted by the findings on alcohol use among athletes [17]. College athletes are often reported to engage in higher and more risky alcohol use than their non-athlete peers [18-20], and it was found that one of the most frequently described reasons for alcohol use among athletes was to alleviate the stress of college life [17]. Due to the previous findings suggesting freshmen athletes experience unique stressors [13], this study will assess the impact of academic class on depression symptom severity. As the physical and academic demands are increased during a team's competitive season, this study will also assess whether depression 
symptom severity differs between in-season and off-season athletes.

\subsection{Injury and Athletic Identity}

Injuries are one of the risks athletes face every day as a part of their athletic commitments, with $40 \%-50 \%$ of athletes facing at least one injury resulting in significant loss in participation during their college years [21]. Through interviews conducted with athletes who had attempted suicide after suffering an injury, Smith and Milliner [22] identify common factors that exist between the athletes post injury. These include a perceived decrease in their athletic skills following their rehabilitation programs, a feeling of being replaced by a teammate, and a lack of pre injury ability following their return. It has also been shown that athletes are particularly susceptible to feelings of depression immediately following an injury [23-26]. However, it has been noted that athletes with greater restrictions regarding their physical activity at 3 months post injury report higher depression scale scores [23], suggesting an enduring nature to these feelings. Athletes with major injuries have also been shown to present with higher levels of perceived stress and lower overall life satisfaction than athletes with minor or no injuries [27]. This finding strongly suggests that injury is a risk factor in the development of depressive symptoms, possibly at clinically significant levels, and particularly during the early stages of recovery.

Injury has also been suggested to challenge an athlete's identity, as they are unable to participate in the activity that once defined their social role [14]. Strength of athlete identity has been linked to higher depression following a role-disrupting event, such as injury [28]. It should be noted that certain studies have shown that in the absence of an event such as injury, the strength of identification with the role of athlete was inversely related to feelings of depression and suicidal ideation [29]. However, it has been proposed that, since athletes often have little opportunity to socialize or explore an identity outside of athletics, they potentially over identify as an athlete [30]. This identity could potentially cause increased feelings of social isolation and mood disturbance following a role-disrupting life event.

Injury represents one of the clearest risk factors for the development of depression in college athletes. Therefore, in order to advance the understanding of the specific role of injury on depression symptoms, participants will be asked questions regarding their history of injury, including if, and how long, they were unable to compete because of any injury suffered.

\subsection{Fear of Failure}

Fear of athletic failure presents another stressor that, in a college setting, is unique to athletes. The discrepancies that may exist between an athlete's desired goal and actual performance outcome can be a cause of significant psychological distress [31]. While perfectionism is an incredibly complex topic with many different dimensions affecting athletes in both positive and negative ways [32], certain perfectionist tendencies - such as excessive worrying about mistakes-have been shown to be related to lower self-esteem and performance satisfaction in athletes [33]. When combined with the poor coping techniques often exhibited by college athletes [13, 17], perfectionism has also been shown to increase vulnerability to depression following athletic failure [34].

Negative game outcome may represent the most frequent example of athletic failure, and it has been linked to significantly higher feelings of depression and anger both immediately post-competition [35] and four to six days later [14]. College athletes can compete in upwards of 50 regular season games per season, creating numerous opportunities for such mood disturbances to take effect. Depressed mood following athletic failure is shown to be particularly prevalent among highly elite performers [36]. The consistent nature of these findings clearly establishes the effect of 
fear of failure and pressure to perform on depression symptoms. Therefore, factors that may be affected by this stressor, such as scholarship received and the competition status of sport will be assessed in this study.

\subsection{Mental Health Care Accessibility and Education}

Student affairs professionals have previously been encouraged to watch for the warning signs of alcohol abuse and signs of depression or other psychological distress among college athletes, particularly in female and freshmen athletes [8]. Recommendations were also made regarding the recognition of warning signs and ways in which to monitor at-risk college athletes - even suggesting that depression screenings be conducted at regular points throughout the athletic season. Despite these suggestions, there are currently no specific requirements for NCAA athletic programs to educate their athletes about mental health. Athletic programs are not required to inform athletes of the issues they may face during their time in college or inform them of how and where to go to receive mental health treatment should they require it.

It has been shown that a lack of awareness in available services and a lack of perceived need of treatment are the two strongest predictors for college students not accessing mental health services [37]. This lack of awareness presents the possibility that college athletes assume symptoms of depression are normal reactions to the significant daily demands of college athletics and are therefore unworthy of treatment, further reducing the likelihood of them seeking help. Increasing the awareness of mental health issues through education and the promotion of available resources can increase the awareness and recognition of mental illness [38]. Educational and contact interventions have also been successful in reducing the stigma around mental health—notably still present in athletics [11] and a significant barrier to accessing treatment [39] — and have led to improvements in overall attitudes about mental health treatment [40].
Evidence therefore suggests that adequate education and exposure to mental health resources will increase college athletes' awareness and recognition of potential mental health issues. In order to determine how effectively athletic programs are communicating these services to their athletes, this study will assess athletes' opinions regarding the availability and accessibility of mental health services for athletes at their universities. Athletes will also be asked whether they have received any education regarding mental health from their athletic department and whether they feel their program would support them through a mental health issue.

\subsection{Current Study}

The purpose of this study was to assess the current prevalence of depression symptoms among college athletes across gender, academic class, scholarship level, and sport season status. The impact of injury, missing practice or competition due to injury, and the length of time missed due to injury on depression symptoms was also assessed. Finally, this study determined athletes' opinions regarding the availability and accessibility of mental health treatment and education within their athletic department.

Existing research has identified significant factors unique to college athletes that may lead to the development of depression in college athletes, such as increased daily stressors [13, 15, 41], injury [22, 23, 25, $27,42,43]$, overreliance on athletic identity [28, 30], and fear of failure [14, 35, 36, 45]. Existing research has also pointed to a lack of awareness regarding available mental health care among college students [37], and this, combined with the stigma that exists regarding mental health issues in athletics [11], may further contribute to college athlete's risk of developing depression. Current research into the actual prevalence rate and individual risk factors for college athletes is inconsistent $[34,44,46]$ with varying results and methodology. However, the most recent studies suggest a higher rate of clinically relevant depressive 
symptoms than previously thought [4] highlighting the need for further investigation in this area. In order to extend the literature on the prevalence and risk factors of depression symptoms in college athletes, this study will replicate aspects of a previous research study in the field [44], while simultaneously building on this research to add to the understanding of the relationship between depression and NCAA sport participation.

Based on past research, numerous hypotheses were made for this study:

Current prevalence of depression symptoms among NCAA division I athletes is as high or higher than the rate of $14 \%-21 \%$ observed in previous studies $[3,44$, 46].

Female athletes will experience more severe depression symptoms than male athletes.

The severity of depression symptoms will differ significantly between academic classes.

Due to the increased pressure to perform placed on scholarship athletes, scholarship status will have a significant effect on depression score.

Due to the increased fear of failure and pressure to perform associated with regular in-season competition, and the significant physical and time demands placed on in-season athletes, in-season athletes will experience more severe depression symptoms than off-season athletes.

Athletes with a history of injury at any point in their career will experience more severe depression symptoms than healthy athletes.

Athletes with a history of injury in the previous 6 months will experience more severe depression symptoms than healthy athletes.

Missing practice due to injury will increase the depression score and that depression scores will also increase in relation to length of time out with injury.

\section{Methods}

\subsection{Participants}

A total of 1,169 NCAA athletes responded to the online survey. However, 219 respondents either dropped out or only partially completed the questionnaires, leaving a sample of 950 participants. Participants were 327 males (34.4\%), 622 females $(65.5 \%)$, and $1(0.1 \%)$ unreported $(0.1 \%)$. The majority, $83.9 \%$ of participants identified as Caucasian/White $(n$ =796), 5.8\% identified as Black/African American ( $n$ $=55), 3.7 \%$ Latino/Hispanic $(n=35), 3.1 \%$ Asian America $(n=29), 0.4 \%$ Native American $(n=4)$, and $3.2 \%$ Other $(n=30)$.

All participants were NCAA Division I athletes. This included $30.5 \%$ freshmen $(n=290), 25.8 \%$ sophomores $(n=245), 24.1 \%$ juniors $(n=229), 17.1 \%$ seniors $(n=162), 2 \%$ graduate students $(n=18)$, and $0.5 \%$ other $(n=5)$.

A variety of scholarship levels were observed, with $24.9 \%$ of participants receiving full scholarship $(n=$ 237), $47.6 \%$ receiving partial scholarship $(n=452)$, $27.4 \%$ with no scholarship $(n=260)$, and one unreported case. $45.5 \%$ reported their sport as being off-season $(n=432)$ and $55.5 \%$ reported currently being in season $(n=518)$. Forty percent $(40.8 \%)$ of the participants had suffered an athletic injury in the last 6 months, with $82.4 \%$ of them having to miss practice or competition due to the injury. Of those participants who were injured, $52.5 \%$ missed less than a month, $33.9 \%$ missed between 1 and 6 months and $12.6 \%$ missed more than 6 months.

\subsection{Measures}

\subsubsection{Background Information Questionnaire}

Participants reported demographic information [i.e., race, sex, academic class] as well as information related to their sport standing, including questions related to academic class, scholarship level, history of injury, and previously diagnosed depression. Included in this questionnaire were questions related to their depression history as well as any information they have received on depression or about the accessibility of mental health services within their athletic program. These questions will be measured on a 1-5 scale from strongly disagree to strongly agree. 


\subsubsection{Center for Epidemiological Studies Depression} Scale

The Center for Epidemiological Studies Depression Scale (CES-D; 47) scale is a 20-item, self-report questionnaire asking participants the extent to which they have experienced a variety of symptoms - such as feeling lonely, feeling worthless, or experiencing crying spells-during the previous week. Responses are rated on a 4-point scale, from 0 (less than once a week) to 3 (5-7 days a week). A total score, out of 60, is calculated from the summation of all 20 items (certain questions are reverse scored), with higher scores indicating more severe symptoms of depression. A total score of 16 or higher indicates the diagnostically significant presence of depression. This measure has been validated for use with the college student population [48].

\subsection{Procedure}

A list of all current NCAA Division I colleges were obtained from the NCAA website. Contact information for every coach was then found via the schools' athletics staff directory pages. A coach from every NCAA Division I program was then contacted via email to request their athletes' participation. The email asked coaches to forward a link to their athletes that they could click to complete the survey on Qualtrics. The survey included an informed consent form, a background questionnaire, and the CES-D. Athletes were not required to provide their name nor any other potential identifying information, including sport played or name of school to increase the participants comfort with filling out the truly anonymous questionnaire. Following completion of the survey, participants were encouraged, via a final page of the questionnaire, to seek professional mental health care if they identified with the symptoms addressed in the CES-D.

\section{Results}

\subsection{CES-D Scores and Non Sport-Related Demographics}

A total of $315(33.2 \%)$ participants reported a depression score of greater than 16, indicating the presence of depression symptoms, with $8.7 \%$ (91) scoring $\geq 30$ (Table 1). To analyze the effect of sex on CES-D scores, an independent T-test was performed. A significant difference was found for sex, $t(947)=-3.30$, $P=0.00 . \quad$ Female athletes $\quad(m=14.46, \quad S D=10.64)$

Table 1 Frequency of CES-D scores $\geq 16$.

\begin{tabular}{lllll}
\hline Independent Variable & & $n$ & $n$ (CES-D score $\geq 16)$ & \% of $n$ (CES-D score $\geq 16)$ \\
\hline Sex & & & 87 & 26.6 \\
& Male & 327 & 228 & 36.6 \\
\hline Academic Class & Female & 622 & & 34.4 \\
\hline & Freshman & 290 & 100 & 34.7 \\
& Sophomore & 245 & 85 & 31.9 \\
& Junior & 229 & 73 & 30.2 \\
& Senior & 162 & 49 & 33.3 \\
& Graduate & 18 & 6 & 40.0 \\
\hline Season Status & Other & 5 & 2 & 30.8 \\
\hline & & & 35.1 \\
\hline Scholarship Level & In Season & 432 & 133 & 35.4 \\
\hline & Off-Season & 518 & 182 & 33.4 \\
& Full & & 84 & 30.8 \\
\hline & Partial & 452 & 151 & 80 \\
\hline
\end{tabular}

No significant difference was found for scholarship level $(P>0.05)$. 
reported significantly higher rates of depression symptoms than male athletes $(m=12.10, S D=10.10)$. Although originally expected to be a variable of interest for the study, race was not included as an independent variable due to unequal sample sizes.

\subsection{CES-D Scores and Sport-Specific Demographics}

Due to the high number of freshman and sophomore participants in the final sample-compared to the junior, senior, and graduate categories of the Academic Class - this variable was unequal in sample size. To deal with this issue, the means of the juniors, seniors, and graduate students were analyzed, and a one-way ANOVA was run to see if there were any significant differences among these groups. No significant differences were found $(P>0.05)$, therefore the data was collapsed into one group labeled upperclassmen. It was also found that the freshman and sophomore categories presented with the same mean scores; therefore, these two categories were combined to a single group labeled lowerclassmen. Participants who listed their academic class as other were disregarded for the analysis, due to the small size of the sample ( $\mathrm{n}=$ $5)$. In order to analyze the effect of sport-related characteristics, a

Univariate ANOVA (2 (academic class) $\times 3$ (scholarship level) $\times 2$ (time of season)) was run. A significant difference was found for academic class, $\mathrm{F}$ $(1,932)=6.67, P=0.01, \eta^{2}=0.01, \beta=0.73$. Lowerclassmen $(\mathrm{m}=14.36, \mathrm{SD}=11.08)$ reported significantly higher rates of depression symptoms than upperclassmen $(\mathrm{m}=12.74, \mathrm{SD}=9.65)$. A significant difference was also found for sport season status, F (1, 932) $=3.98, P=0.05, \eta^{2}=0.004, \beta=0.51$. Athletes in the off-season $(\mathrm{m}=13.14, \mathrm{SD}=10.39)$ reported significantly lower rates of depression symptoms compared to in-season athletes $(\mathrm{m}=14.10, \mathrm{SD}=$ 10.60).

\subsection{CES-D Scores and Injury}

A series of $t$ tests were run to analyze the effect history of injury had on CES-D scores. Multiple $t$ tests were chosen over Univariate ANOVA as different participants qualified for different analyses. For example, only those who answered yes when asked if they had suffered an injury, either ever or in the previous 6 months, were prompted to respond to questions regarding the severity and duration of that injury. If an ANOVA had been used, only those who qualified for all questions would have been

Included in the analysis. First, a $t$ test was run to investigate whether there was a significant difference based on whether athletes had ever suffered an injury $(P>0.05)$. However, a significant difference was found between athletes with a history of injury in the previous 6 months and those without a injury in the last 6 months, $t(784)=2.01, P=0.05$. Athletes who had suffered an injury in the previous 6 months ( $m=14.49$, $S D=10.99)$ reported significantly higher levels of depression symptoms than those who had remained healthy during this time $(m=13.07, S D=10.12)$. A further $t$ test was performed to determine whether, for those who had suffered an injury in the last 6 months, missing practice or competition due to this injury affected depression scale scores. A significant difference was found $t(155)=4.16, P=0.00$, suggesting that those who were forced to miss activity ( $m=15.30, S D=11.52$ ) scored significantly higher on the CES-D than those who did not $(m=10.85, S D=$ 7.04).

A Univariate ANOVA was conducted to determine the effect of the duration of an athlete's injury on CES-D score, based on < 1-month, 1-3 months, 3-6 months, and 6+ months intervals. No significant difference was found between these intervals. However, analysis of the means suggests that athletes who are injured for less than 1 month ( $m=15.84, S D=11.96$ ) or for longer than 6 months $(m=16.25, S D=10.65)$ generally report higher depressive symptoms scores than those who are injured for 1-3 months ( $m=13.69$, $S D=10.99)$ or 3-6 months $(m=14.92, S D=11.46)$. 


\subsection{Mental Health Care Accessibility and Education}

The descriptive for each of the questions regarding mental health availability, accessibility, and education were analyzed. The results showed that, of the four questions asked, athletes agreed most strongly that the athletic department would support them through a mental health issue $(\mathrm{m}=3.90, \mathrm{SD}=0.96)$. Overall, $72.9 \%$ of athletes either agreed or strongly agreed with this statement. Participants generally agreed that mental health care was easily available to themselves or other athletes at their university $(\mathrm{m}=3.69, \mathrm{SD}=$ 0.93 ) and that they knew how or where to access treatment $(\mathrm{m}=3.57, \mathrm{SD}=1.14)$. However, a total of $25.7 \%$ either disagreed or strongly disagreed with this statement. A total of $44.5 \%$ also disagreed or strongly disagreed that they had received any education about mental health as a college athlete $(\mathrm{m}=2.92, \mathrm{SD}=$ 1.16).

\section{Discussion}

\subsection{Overall Depression Prevalence}

One of the main intentions of this study was to determine a prevalence rate of depressive symptoms among college athletes. The observed rate of $33.2 \%$ supported the hypothesis that the rate of depression symptoms in college athletes is higher than has been reported in previous studies of this population. These studies have shown the prevalence rate to range from 14\%-23.7\%, depending on the methods and measures used $[3,46,47]$. The discrepancy between the results obtained in this study and previous findings suggests that depression may be an issue that affects far more college athletes than previously thought. The findings of this study align much closer to the suggested 30\% prevalence rate experienced by the general college population (ACHA, 2014). These findings may contradict previous suggestions that participation in college athletics may serve as a protective factor against mental illness [46, 49]. Although a CES-D score of 16 or higher does not represent a clinical diagnosis of depression, scores have been shown to correlate highly with results of similar self-report depression screenings such as the Beck Depression Inventory [50], and it remains a widely used measure of depression symptoms. Therefore, the finding that one third of athletes reported a score indicating the presence of at least mild depression symptoms is potentially noteworthy.

A possible reason for the increased prevalence rate of depression symptoms observed in this study is the high level of anonymity given to participants [51]. No identifying information was requested during the survey, and this may have allowed participants to report more honestly than in previous studies conducted at a single institution [44] or those only comprising athletes from a single sex or sport [46]. It is also possible that, due to the recent exposure mental health issues have received in the press [1,2], athletes are more aware of these issues and therefore are more likely to acknowledge negative emotions when asked to report them. However, the fact that only $8.3 \%$ of participants indicated they had ever been diagnosed with depression, and just $3.7 \%$ had been diagnosed in the previous 6 months, suggests that the percentage of athletes actually reporting these symptoms to health professionals is very low. In comparison, the diagnosis rate of depression among college students in the previous 12 months, as reported by the ACHA [7], is $12 \%$. This study, therefore indicates that although athletes appear to experience depression symptoms at a similar rate as non-athletes, approximately $30 \%$, they are less likely to seek help and receive a clinical diagnosis.

Due to the low response rate of less than one percent of the total college athlete population and as, in an effort to truly maintain anonymity, no demographic information regarding school or sport was requested, there is no way to determine how representative this sample is of the Division I college athlete population. However, this study does represent the largest sample of depression in college athletes for studies of this kind 
[3, 4, 44, 46], including male and female college athletes from a variety of sports and universities. Moreover, the reported response rate was derived from the total number of Division I athletes. As this study utilized team coaches as an initial point of contact, and requested their cooperation to distribute the survey link to their athletes, there is no discernable way to measure the exact number of athletes reached by the study. Certain institutions and individual coaches actively indicated their declination to participate, reducing the overall number of potential participants. Therefore, it is likely the actual response rate from those athletes who were sent the questionnaire was higher than the initial $0.8 \%$ reported.

The findings of this study are also supported by the results of Wolanin et al.'s [4] recent research, from which it was found that levels of clinically relevant depressive symptoms among college athletes are higher than previously thought, and suggested to be comparable to prevalence rate observed in the general population. This finding was obtained using CES-D scores collected from routine spring sport physicals, from a sample of 465 athletes, and achieved a high participation rate from the athletes at that institution. The current study aimed to draw a representative random sample of the college athlete population by surveying from a number of institutions across the country, and was able to garner significant participation from all four undergraduate academic classes- noted limitations of Wolanin et al's study [4]. Despite the differences in methodology, the similar nature of the findings regarding the prevalence rate of clinically relevant depressive symptoms in college athletes observed in recent research [4], adds to the possibility that the results from the current study may be an accurate depiction of this issue rather than solely the product of self-selection bias. However, further research is needed to address this question more thoroughly. It should be noted that concern for the issue of depression in college athletes has since been further acknowledged by the NCAA, who recently published
Mental Health Best Practices [52], providing materials and recommendations for pre participation mental health screenings for a number of mental health issues, including depression.

\subsection{Individual Risk Factors for Depression Symptoms}

\subsubsection{Sex}

Analysis of the potential demographic risk factors on depression symptom prevalence provided some significant findings. The findings from the current study support the hypothesis that female athletes experience significantly higher levels of depression symptoms than male athletes. This is in accordance with trends observed in the general population and from previous studies involving college and elite athletes [4, 31, 44]. This finding was, nevertheless, noteworthy and may have several explanations. Female athletes are more likely to participate in aesthetic sports, such as swimming, diving, or gymnastics - all sports that were contacted for participation in this survey. It has previously been suggested that participation in these sports may be consistent with higher depression and anxiety scores [31]. Women are also diagnosed with and seek treatment for depression at a higher rate than men in the general population. However, the simple fact that female athletes are consistently reported to be at an increased risk of experiencing depression symptoms highlights the need for improved screening practices and treatment within female athletic programs.

\subsubsection{Academic Class}

The third hypothesis, stating that depression symptoms will differ between academic classes was supported. It was found that underclassmen reported statistically significantly higher CES-D scores than upperclassmen. It has been previously suggested that freshman athletes are particularly susceptible to feelings of depression, due to the many challenges that accompany adjusting to college life [41]. These can include acclimating to a new location, being homesick, integrating into a new team, forming relationships with 
new teammates and coaches, and the losing the star-athlete status experienced in high school [13]. However, as freshmen and sophomores reported equal means and therefore could be combined into one category, it is possible that these feelings and issues may have an enduring effect that extends beyond freshman year. Many of these factors may dissipate over time, such as homesickness and needing to develop relationships with new coaches, explaining the lower scores reported by upperclassmen, but may not have been fully resolved by the end of athlete's freshman year. It has also previously been suggested that freshmen and sophomore students may exhibit higher reactions to academic stress compared juniors and seniors, as they may not have developed adaptive coping mechanisms, and may lack the strong social networks used to deal with college stress by upperclassmen [53]. This may indicate that underclassmen, as a group, are more at risk for depression symptoms than are just freshmen, as previously thought. Therefore particular attention needs to be paid to the mental health of both freshmen and sophomores as they try to fully adjust to the rigors of college athletics.

\subsubsection{Scholarship}

The fourth hypothesis, regarding the effect of scholarship level on depression symptoms, was not supported, as no difference was observed. However, the lack of statistically significant difference between scholarship levels was, in and of itself, significant. It has been proposed that scholarship athletes experience less freedom that non-scholarship athletes [54] and may perceive more pressure or expectation on their performance. Thus, it was expected that they would experience increased depression symptoms. However, no difference was found; suggesting that, while scholarship may affect one's motivation and enjoyment of sport, it may not cause clinically significant psychological distress.

\subsubsection{Season Status}

Season status was shown to significantly affect depression scores, as athletes who were in season reported significantly higher depression scores than those in the off-season, supporting the stated hypothesis. Many of the daily stresses of college athletics are heightened during short and intense collegiate seasons [16]. Significant time spent traveling to and from competitions reduces available time for activity outside of sport. Frequent in-season competitions may increase pressure to perform, fear of failure, and provide multiple opportunities to experience negative game outcome and any subsequent psychological distress related to that outcome $[14,35$, $36,45]$. These are issues that are less likely to be experienced in the off-season. As data collection occurred during spring semester, it is possible that fall-sport athletes were able to relax after the completion of their seasons and were less stressed by their reduced daily athletic commitments than their in-season counterparts. Although athletes engage in off-season training programs, the decreased activity schedule permitted under NCAA compliance regulations and lack of competitive contests may reduce the daily demands on an athlete's time and effort. This shows that athletic programs should be aware that athletes are vulnerable to increased psychological distress during their competitive season, and measures should be developed to identify and monitor those experiencing symptoms of depression during this period.

\subsubsection{Injury}

The results from this study supported the hypothesis predicting increased depressive symptoms among athletes who had suffered an injury in the previous 6 months. This closely aligns with the findings of previous research [22, 23, 25, 27, 28, 43]. However, new to this study was the statistically significant support for the hypothesis that athletes who were unable to practice or compete because of an injury suffered in the previous 6 months experienced more severe depression symptoms than those who were able to continue practicing. This highlights the potential 
psychological distress caused by the act of missing out on practice or competition. It implies that removing the athlete from activity may have more of a negative psychological effect than the physical limitations or pain associated with an injury. Being unable to physically compete represents a significant disruption to the athletes' social role as well as leads to increased feelings of depression in those who most strongly identify with this role [28].

Interestingly, the hypothesis regarding the effect of experiencing an injury at any point in ones' athletic career was also not supported, as this factor was found to have no significant effect on the depression score. This result implies that one may recover from the psychological impact of injury over time but that recent history of injury is of particular significance with respect to the development of depression symptoms. Although symptoms may dissipate over time, experiencing depression symptoms can result in a number of immediate negative consequences to the individual, ranging from impairment of academic performance [55] to an increased risk of suicide [56]. Therefore, it is vital that any athlete experiencing symptoms of depression following an injury receives treatment rather than being allowed to assume they will simply recover over time.

The results from this study further demonstrate that athletes are at an increased risk for depression symptoms following a recent injury. However, the findings also show that this risk is significantly higher if the athlete is forced to miss practice or competition due to their injury, regardless of the amount of time they miss. This finding suggests that it is important to administer depression screenings for all athletes who suffer an injury, and it is especially important to administer these screenings at various times throughout the rehabilitation process for athletes who are forced to miss activity. It also emphasizes the importance of integrating and involving injured athletes in all team activities, including practice and competition, as a way to minimize the negative effects of their injury-forced absence.

\subsection{Mental Health Care Accessibility and Education}

An aspect of this study that was unique compared to previous research was the investigation of opinions regarding current mental health care availability, accessibility, education, and support. Due to the recent promotion of these issues by the NCAA, it was important to gain an understanding of how mental health care is currently experienced by athletes. The results from these questions present some cause for concern. It was found that $25.7 \%$ of studentathletes sampled did not know how, or where, to access mental health treatment at their university, and over $44 \%$ of athletes had not received any mental health education through their athletic department. These findings are particularly poignant, as understanding these issues and knowing where to receive treatment are vital aspects of effective mental health care. This points to a significant deficiency in the mental health services provided by collegiate athletics programs.

Inversely, athletes generally felt that their athletic department would support them through any mental health issue, with only $9.8 \%$ of participants indicating they disagreed or strongly disagreed with this sentiment. It was also found that most athletes felt treatment was available to them or other athletes should they need it, with just $11.6 \%$ disagreeing or strongly disagreeing with this statement. This presents an interesting contradiction, wherein the majority of athletes do feel care is available and would feel supported by their athletic department if they suffered a mental health issue, but many do not actually know where to get this care and have received little to no education of why they might need it. It therefore appears clear that increasing mental health education for college athletes and increasing their knowledge regarding the accessibility of services should be a significant area of focus for athletic departments and administrations. 


\subsection{Recommendations for Future Research}

The findings from this study present several potential avenues for further research. One such avenue would be to extend the methodology of this study to include NCAA Division II and III athletes. This would not only give researchers a national prevalence rate for all college athletes but would also allow for comparison of risk factors between divisions, which may well differ significantly based on the differing pressures and stressors experienced by each group. As mentioned above, sport was not a variable measured in the study. This was, in part, to maintain anonymity for athletes and encourage honest reporting of their symptoms. However, in order to develop the most thorough analysis of risk factors, sport-specific differences may be a variable that warrants investigation.

The prevalence rate of depression symptoms among athletes observed in this study and a diagnosis rate far lower than the general college population suggest a significant need to examine how these issues are reported. Research should focus on identifying any barriers that may exist specific to college athletics. A concerted effort also needs to be made to develop effective mental health education programs for athletes, focused on increasing awareness and reducing the stigma surrounding mental health. Research also needs to be conducted into how symptoms are recognized and treated within the team environment. While it is possible athletes are able to mask their symptoms during team activities, it is also possible that athletic trainers and coaches are either ignoring or unable to recognize these symptoms. Education programs should therefore extend to coaches and athletic trainers to increase their understanding and ability to recognize depression symptoms in their athletes.

\section{Conclusions}

To the researchers' knowledge, this study represents the largest investigation into the prevalence of depression symptoms in college athletes to date.
Therefore, the results present several unique findings that could significantly advance the topic of depression in college athletics. The high prevalence rate observed in this study indicates that depression is a more significant issue in college athletics than previously acknowledged. However, the low rates of diagnosed depression in the past 6 months also indicate a potential reluctance to seek treatment. It appears that athletes are not receiving adequate education from their athletic department on issues regarding their mental health. This study has highlighted specific groups of NCAA Division I athletes who are at an increased risk for the development of depression symptoms. Female athletes, underclassmen, in-season athletes, athletes who experience injury, and athletes who miss practice or competition due to that injury are all shown to be susceptible to increased depression symptomatology. Improving mental health awareness, particularly among these at-risk groups, should be of the utmost importance going forward. Similarly, the development of regular depression screening and treatment procedures to adequately address these risks should be strongly considered. By not requiring athletic departments to provide any mental health education to their athletes, either in terms of the factors that may increase susceptibility to mental illness or of the services that are available to them, administrations are potentially increasing the possibility that symptoms will go unreported and athletes will fail to receive the care that they need.

\section{Acknowledgement}

The authors would like to acknowledge Alexa Knuth, and Corinne Brent for their help with this research. Without them this research would not have been possible.

\section{References}

[1] Flanagan, L. 2014. When College Athletes Face Depression. Accessed March 21, 2014. http://www.theatlantic.com/education/archive/2014/03/w hen-college-athletes-face-depression/284484/. 
[2] Noren, N. 2014. "Taking Notice of the Hidden Injury." Accessed October 24, 2014. http://espn.go.com/espn/otl/story/_/id/10335925/awarene ss-better-treatment-college-athletes-mental-health-beginstake-shape.

[3] Weigand, S., Cohen, J., and Merenstein, D. 2013. "Susceptibility for Depression in Current and Retired Student Athletes." Sports Health: A Multi-Disciplinary Approach 5 (3): 263-6.

[4] Wolanin, A., Hong, E., Marks, D., Panchoo, K., and Gross, M. 2016. "Prevalence of Clinically Elevated Depressive Symptoms in College Athletes and Differences by Gender and Sport." British Journal of Sports Medicine 50 (3): 167-71.

[5] Kessler, R. C., Berglund, P., Demler, O., Jin, R., Merikangas, K. R., and Walters, E. E. 2005. "Lifetime Prevalence and Age-of-Onset Distributions of DSM-IV Disorders in the National Comorbidity Survey Replication." Archives of General Psychiatry 62 (7): 593-602.

[6] National Alliance on Mental Illness. 2012. "College Students Speak: Survey Report on Mental Health." $\begin{array}{llll}\text { Accessed } & \text { October } & 24,\end{array}$ www.nami.org/collegereport.

[7] American College Health Association. 2014. American College Health Association- National College Health Assessment II: Reference Group Executive Summary Spring 2014. Hanover, MD: Author.

[8] Etzel, E. F., Watson, J. C., Visek, A. J., and Maniar, S. D. 2006. "Understanding and Promoting College Student-Athlete Health: Essential Issues for Student Affairs Professionals." NASPA Journal 43 (3): 518-46.

[9] Pinkerton, R. S., Hinz, L. D., and Barrow, J. C. 1989. “The College Student-Athlete: Psychological Considerations and Interventions." Journal of American College Health 37 (5): 218-26.

[10] Terlep, S. 2014. "The Mental Health of the College Athlete." Accessed January 19, 2015. http://www.wsj.com/articles/the-mental-health-of-the-coll ege-athlete-1417469413.

[11] McLean, B. 2014. Stigma of Mental Health in Sports Remains an Opponent. Accessed March 21, 2014. http://www.nami.org/template.cfm?Section=home\%20\&t emplate $=/$ ContentManagement/ContentDisplay.cfm\&Con tentID $=166507 \& 1$ stid $=837$.

[12] Watson, J. C. 2005. "College Student-Athletes Attitudes toward Help-Seeking Behavior and Expectations of Counseling Services." Journal of College Student Development 46 (4): 442-49.

[13] Papanikolaou, Z., Nikolaidis, D., Patsiaouras, A., and Alexopoulos, P. 2003. "The Freshman Experience: High Stress-Low Grades." Athletic Insight: The Online Journal of Sport Psychology 5 (4). Accessed April 4, 2005.
http://www.athleticinsight.com/Vol5Iss4/Commentary.ht $\mathrm{m}$

[14] Jones, A. L., Butryn, T. M., Furst, D. M., and Semerjian, T. Z. 2013. "A Phenomenological Examination of Depression in Female Collegiate Athletes." Athletic Insight: The Online Journal of Sport Psychology 15 (1): 1-19.

[15] Hudd, S., Dumlao, J., Erdmann-Sager, D., Murray, D., Phan, E., Soukas, N., and Yokozuka, N. 2000. Stress at College: Effects on Health Habits, Health Status and Self-Esteem. College Student Journal 34 (2): 217-27.

[16] Humphrey, J. H., Yow, D. A., and Bowden, W. W. 2000. Stress in College Athletics: Causes, Consequences, Coping. Binghamton: Haworth Half-Court Press.

[17] Evans, M., Weinberg, R., and Jackson, A. 1992. "Psychological Factors Related to Drug Use in College Athletes." The Sport Psychologist 6 (1): 24-41.

[18] Brenner, J. and Swanik, K. 2007. "High Risk Drinking Characteristics in College Athletes." Journal of American College Health 56 (3): 272-6.

[19] Nelson, T. F., and Wechsler, H. 2001. "Alcohol and College Athletes." Medicine \& Science in Sports \& Exercise 33 (1): 43-7.

[20] Yusko, D. A., Buckman, J. F., White, H. R., and Pandina, R. J. 2008. "Risk for Excessive Alcohol Use and Drinking-Related Problems in College Student Athletes." Addictive Behavior 33 (12): 1545-56.

[21] Meeuwisse, W. H., Selmer, R., and Hagel, B. E. 2003. "Rates and Risk of Injury during Intercollegiate Basketball." American Journal of Sports Medicine 31 (3): 379-85.

[22] Smith, A. M., and Milliner, E. K. 1994. "Injured Athletes and the Risk of Suicide." Journal of Athletic Training 29 (4): 337-41.

[23] Appaneal, R. N., Levine, B. R., Perna, F. M., and Roh, J. L. 2009. "Measuring Post Injury Depression among Male and Female Competitive Athletes." Journal of Sport \& Exercise Psychology 31 (10): 60-76.

[24] Fallon, B. J., and Quinn, A. M. 1999. "The Changes in Psychological Characteristics and Reaction of Elite Athletes from Injury Onset until Full Recovery.” Journal of Applied Sports Psychology 11 (2): 210-29.

[25] Manuel, J., Shilt, J., Curl, W., Smith, J., DuRant, R., Lester, L., and Sinal, S. 2002. "Coping With Sports Injuries: An Examination of the Adolescent Athlete." Journal of Adolescent Health 31 (5): 391-3.

[26] Tracey, J. 2003. "The Emotional Response to the Injury and Rehabilitation Process." Journal of Applied Sport Psychology 15 (4): 279-93.

[27] Malinauskas, R. 2010. "The Associations among Social Support, Stress, and Life Satisfaction Perceived by Injured College Athletes." Social Behavior \& Personality: An 
International Journal 38 (6): 741-52.

[28] Brewer, B. W. 2007. "Psychology of Sport Injury Rehabilitation". In Handbook of Sport Psychology 3rd Edition, edited by Tennenbaum, G. S., and Eklund, R. C. Hoboken: John Wiley \& Sons, 404-24.

[29] Miller, K. E., and Hoffman, J. H. 2009. Mental Well-Being and Sport-Related Identities in College Students. Sociology of Sport Journal 26 (2): 335-56.

[30] Watson, J. C., and Kissinger, D. B. 2007. "Athletic Participation and Wellness: Implications for Counseling College Student-Athletes." Journal of College Counseling 10 (2): 153-62.

[31] Schaal, K., Tafflet, M., Nassif, H., Thibault, V., Pichard, C., Alcotte, M., and Toussaint, J. F. 2011. "Psychological Balance in High Level Athletes: Gender-Based Differences and Sport-Specific Patterns." PLoS One 6 (5): e19007.

[32] Koivula, N., Hassmén, P., and Fallby, J. 2002. "Self-Esteem and Perfectionism in Elite Athletes: Effects on Competitive Anxiety and Self-Confidence." Personality and Individual Differences 32 (5): 865-75.

[33] Gotwals, J. K., Dunn, J. H., and Wayment, H. A. 2003. "An Examination of Perfectionism and Self-Esteem in Intercollegiate Athletes." Journal of Sport Behavior 26 (1): 17-38.

[34] Hewitt, P. L., and Flett, G. L. 2002. "Perfectionism and Stress Processes in Psychopathology." In Perfectionism: Theory, Research, and Treatment, edited by Flett, G. L., and Hewitt, P. L. Washington, DC: American Psychological Association, 255-84.

[35] Hassmen, P., and Blomstrand, E. 1995. "Mood State Relationships and Soccer Team Performance." Sport Psychologist 9 (3): 297-308.

[36] Hammond, T., Gialloreto, C., Kubas, H., and Hap Davis, H. 2013. "The Prevalence of Failure Based Depression among Elite Athletes." Clinical Journal of Sports Medicine 23 (4): 273-7.

[37] Eisenberg, D., Golberstein, E., and Gollust, S. E. 2007. "Help-Seeking and Access to Mental Health Care in a University Student Population." Medical Care 45 (7): 594-601.

[38] Jorm, A., Christensen, H., and Griffiths, K. 2005. "The Impact of Beyondblue: The National Depression Initiative on the Australian Public's Recognition of Depression and Beliefs about Treatments." Australian \& New Zealand Journal of Psychiatry 39 (4): 248-54.

[39] Corrigan, P. W., Druss, B. G., and Perlick, D. A. 2014. "The Impact of Mental Illness Stigma on Seeking and Participating in Mental Health Care." Psychological Science in the Public Interest 15 (2): 37-70.

[40] Penn, D. L., and Couture, S. M. 2002. "Strategies for Reducing Stigma toward Persons with Mental Illness."
World Psychiatry 1 (1): 20-1.

[41] Wilson, G., and Pritchard, M. 2005. "Comparing Sources of Stress in College Student Athletes and Non-Athletes." Athletic Insight: The Online Journal of Sport Psychology 7 (1). Accessed October 18, 2016. http://www.athleticinsight.com/Vol7Iss1/StressAthletesN onathletes.htm.

[42] Brewer, B. W. 1993. "Self-Identity and Specific Vulnerability to Depressed Mood.” Journal of Personality 61 (3): 343-64.

[43] Gulliver, A., Griffiths, K. M., Mackinnon, A., Batterham, P. J., and Stanimirovic, R. 2015. "The Mental Health of Australian Elite Athletes." Journal of Science and Medicine in Sport 18 (3): 255-61.

[44] Yang, J., Peek-Asa, C., Corlette, J. D., Cheng, G., Foster, D. T., and Albright, J. 2007. "Prevalence of and Risk Factors Associated with Symptoms of Depression in Competitive Collegiate Student Athletes." Clinical Journal of Sports Medicine 17 (6): 481-7.

[45] Jones, M. V., and Sheffield, D. 2007. "The Impact of Game Outcome on the Well-Being of Athletes." International Journal of Sport and Exercise Psychology 5 (2): 54-65.

[46] Proctor, S. L., and Boan-Lenzo, C. 2010. "Prevalence of Depressive Symptoms in Male Intercollegiate Student-Athletes and Nonathletes." Journal of Clinical Sport Psychology 3 (4): 204-20.

[47] Radloff, L. S. 1977. "The CED-D Scale: A Self-Report Depression Scale for Research in the General Population." Applied Psychological Measurement 1 (3): 385-401.

[48] Radloff, L. S. 1991. "The Use of the Center for Epidemiologic Studies Depression Scale in Adolescents and Young Adults." Journal of Youth and Adolescence 20 (2): 149-66.

[49] Armstrong, S., and Oomen-Early, J. 2009. "Social Connectedness, Self-Esteem, and Depression Symptomatology among Collegiate Athletes versus Nonathletes." Journal of American College Health 57 (5): 521-26.

[50] Zich, J. M., Attkisson, C. C., and Greenfield, T. K. 1990. "Screening for Depression in Primary Care Clinics: The CES-D and the BDI." International Journal of Psychiatry in Medicine 20 (3): 259-77.

[51] Ong, D. A., and Weiss, D. J. 2006. "The Impact of Anonymity on Responses to Sensitive Questions." Journal of Applied Social Psychology 30 (8): 1691-708.

[52] National Collegiate Athletic Association. 2016. "Mental Health Best Practices." Accessed May 2, 2016. http://www.ncaa.org/sites/default/files/HS_Mental-Health -Best-Practices_20160317.pdf.

[53] Misra, R., and McKean, M. 2000. "College Students' Academic Stress and Its Relation to Their Anxiety, Time 
Management, and Leisure Satisfaction." American Journal of Health Studies 16 (1): 41-51.

[54] Medic, N., Mack, D. E., Wilson, P. M., and Starkes, J. L. 2007. "The Effects of Athletic Scholarship on Motivation in Sport." Journal of Sport Behavior 30 (3): 292-306.

[55] Heiligenstein, E., Guenther, G., Hsu, K., and Herman, K. 1996. "Depression and Academic Impairment in College Students." Journal of American College Health 45 (2):
59-64.

[56] Isacsson, G., Bergman, U., and Rich, C. L. 1996. "Epidemiological Data Suggest Antidepressants Reduce Suicide Risk among Depressives." Journal of Affective Disorders 41 (1): 1-8.

[57] Rihmer, Z. 2001. "Can Better Recognition and Treatment of Depression Reduce Suicide Rates? A Brief Review." European Psychiatry 16 (7): 406-9. 